\title{
Lehmän mittainen makuuparsipihatto
}

Tapani Kivinen ${ }^{1)}$, Kim O. Kaustel1 ${ }^{2)}$, Timo Hurme ${ }^{3)}$, Kristiina Hakkarainen $^{4)}$, Veli-Matti Tuure ${ }^{5)}$, Janne Karttunen ${ }^{5)}$

${ }^{1)}$ MTT, Kotieläintuotannon tutkimus, Vakolantie 55, 03400 Vihti, tapani.kivinen@mtt.fi

${ }^{2)}$ MTT, Taloustutkimus, Vakolantie 55,03400Vihti, kim.kaustell@mtt.fi

${ }^{3)}$ MTT, Palveluyksikkö, 31400 Jokioinen, timo.hurme@mtt.fi

${ }^{4)}$ Helsingin yliopisto, eläinlääketieteellinen tiedekunta, Kliinisen tuotantoeläinlääketieteen laitos, Saaren yksikkö, Pohjoinen pikatie 800,04920 Saarentaus, kristiina.hakkarainen@helsinki.fi,

${ }^{5)}$ TTS tutkimus, luonnonvara-ala, PL 5,05201Rajamäki,veli-matti.tuure@tts.fi, janne.karttunen@tts.fi

\section{Tiivistelmä}

Laajentavien suomalaisten lypsykarjatilojen rakennusmallit perustuvat pitkälti ulkomaisiin esimerkkeihin. Näiden toiminnallisuus, tehokkuus ja tekniikka on koeteltu alkuperämaassa. Ulkomaiset mallit on yleensä muunneltu sopimaan kotimaiseen työtapaan, tilarakenteeseen, rakennustekniikkaan ja ilmastoon. Lypsykarjatalouden voimakkaan rakennekehityksen vuoksi suomalaisen navetan evoluutiossa on ollut sopiva hetki katsoa, mitä viimeaikaisessa pihattorakentamisessa on tilatasolla saatu aikaan. Käsillä oleva artikkeli perustuu MTT:n, Helsingin Yliopiston, TTS Tutkimuksen sekä Valion kanssa vuosina 2004 2006 tehtyyn Lypsykarjarakennusten toiminnalliset mitoitusvaihtoehdot - nimiseen hankkeeseen. Tutkimuksen rahoittajana toimi Maatilatalouden kehittämisrahasto MAKERA. Tutkimus on tähän asti laajin ja poikkitieteellisin alan kotimainen selvitystyö, jossa kohteena oli 100 uutta ja suurta pihattoa tasapuolisesti eri puolilla maata. Tutkimuksen kohteina olleissa pihatoissa oli yhteensä 11720 nautaeläintä, joista lypsylehmiä $5440 \mathrm{kpl}$.

Laajan kenttäinventoinnin avulla jokaisesta pihatosta havainnoitiin ja tallennettiin noin tuhat erilaista numeerista tietoa. Tietojen keräys kohdistettiin lehmistä mitattaviin seikkoihin, ihmisen työympäristön ominaisuuksiin, karjanhoitotöiden menetelmävertailuun ja tuotantorakennuksen mitoitukseen. Lehmä-ja työympäristödatan väliset vuorovaikutussuhteet mallinnettiin ja käsiteltiin tilastollisesti siten, että pihaton hyvin toimiville ominaisuuksille haettiin selittävät tekijät rakennuksen ominaisuuksista. Hyvin toimivan pihaton mitoitukseen saatiin lukuarvot, joita voidaan tarjota suosituksiksi uusien pihattojen suunnitteluun.

Tutkimuksen keskeisimmät löydökset osoittavat, että toimivan pihaton edellytyksiä ovat lehmän puhtaus ja sorkkaterveys sekä parren mukavuus ja riittävä mitoitus. Syöntirauha, vedensaanti ja riittävä lepo ovat keskeisiä tuotostekijöitä. Lypsyyn, ruokintaan ja muihin karjanhoitotöihin on saatavana runsaasti erilaista tekniikkaa, jonka käytön tehokkuudella on huomattava vaikutus karjanhoitotöiden työnmenekkiin. Työmäärään voidaan vaikuttaa menetelmävalintojen lisäksi töiden organisoinnilla ja tilasuunnittelulla. Työtyytyväisyyden kannalta menetelmävalinnoissa täytyy tasapainoilla tekniikan hyödyllisyyden ja hinnan välillä. Tutkimuksen päätelmissä esitetään pihaton parsien sekä lantakäytävien suunnitteluun uusia, aikaisempaa väljempiä mitoituksia. Nämä mitoitukset vaikuttavat ensisijaisesti vain lypsylehmien osastoon, joten pihaton kokonaismitoitus riippuu edelleen myös muiden valittavien tilaryhmien, kuten lypsy- ja rehujärjestelmän sekä rehunkäsittelytilojen, pinta-alavaatimuksista. Lehmien päivittäin käytössä olevan pinta-alan lievän lisäämisen odotetaan kuolettavan itsensä parantuneella tuotoksella ja vähentyneillä

Avainsanat: pihatto, lypsylehmä, vasikka, ontuminen, ihovauriot, maidontuotos, soluluku, työnmenekki, työtyytyväisyys, hyvinvointi, mitoitus, suunnitteluohje 


\section{Tutkimusmenetelmä}

Tutkimus jakautui menetelmällisesti neljään vaiheeseen. Aluksi laadittiin kirjallisuustutkimuksen sekä asiantuntijayhteistyön avulla lista sellaisista toiminnallisista vaatimuksista, joiden avulla kuvattiin ratkaisuilta haluttavat ominaisuudet tuotantoprosessin, työntekijöiden ja eläinten kannalta.
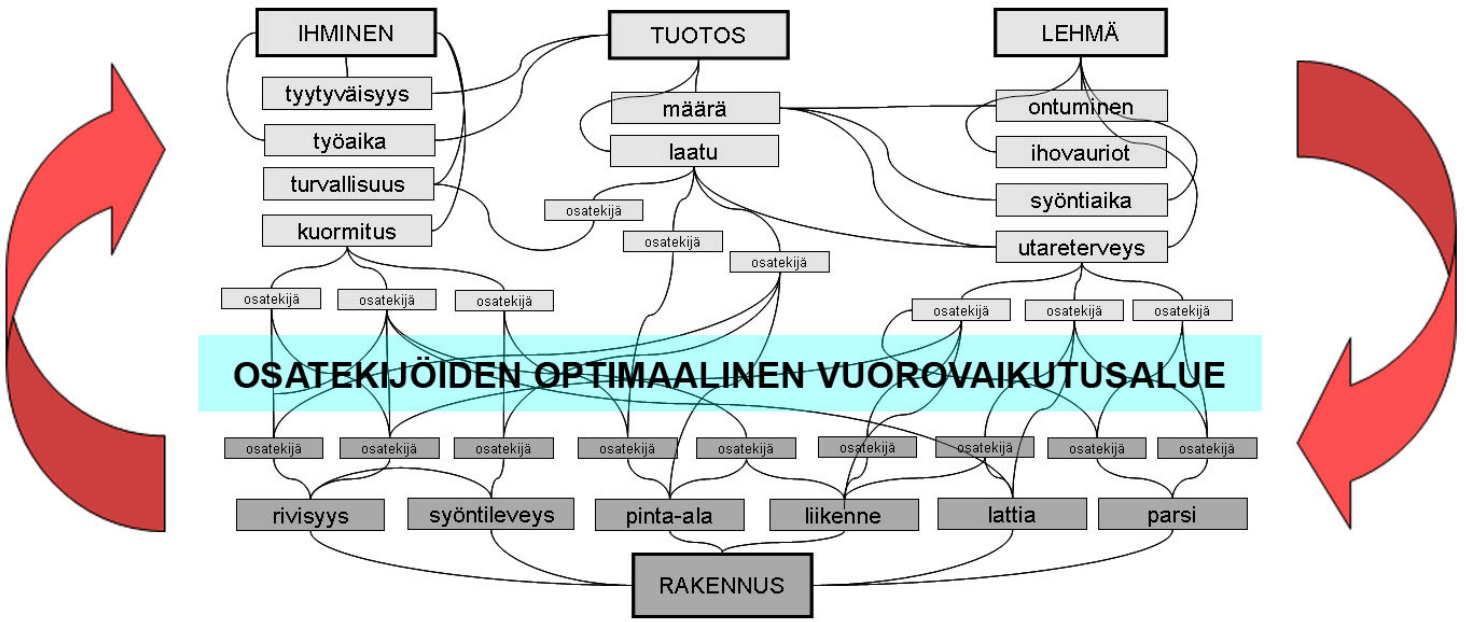

Kuva 1. Teoreettinen malli siitä, miten ihmisen, lehmän ja tuotoksen välisiä muuttujia tarkasteltiin. Keskeisenä ajatuksena oli löytää ihmisen ja lehmän väliset vuorovaikutussuhteet kun ne yhdessä toimivat tuotantorakennuksessa saadakseen aikaan maitotuotoksen. Tuotantorakennuksen fyysiset ominaisuudet vaikuttavat ihmisen ja lehmän toimintaan ja tehokkuuteen, jolloin niiden välimaastosta löytyy niiden positiivisten ominaisuuksien joukko, joista toimivan pihaton voi tunnistaa.

Toisessa vaiheessa pyrittiin määrittelemään kenttäolosuhteisiin soveltuva mittaristo, jonka avulla voitiin todeta, olivatko tehdyt ratkaisut asetettujen vaatimusten mukaisia. Tässä vaiheessa määriteltiin myös mittausmenettelyt sekä laadittiin tiedonkeruulomakkeisto, johon tilakäynneillä kirjattiin havainnot, mittaukset sekä haastattelutulokset.

Tutkimuksen kolmas vaihe oli kenttätyö, jossa edellisessä vaiheessa laadittulla lomakkeistolla analysoitiin 100 pihattokohdetta. Kyselyn perusteella tunnistettujen toiminnallisten ratkaisujen kuvaamiseksi ja todentamiseksi tehtiin tiedonkeruuta tarkentavia tilakäyntejä. Täydentävät havainnoinnit ja mittaukset kohdistettiin esimerkiksi ajankäyttöön, työn kuormittavuuteen, olosuhteisiin tai eläinten käyttäytymiseen ja puhtauteen - yksityiskohtiin, joista vertailukelpoista tietoa oli vaikea saada usean eri havainnoitsijan tekemän tilakäynnin avulla.

Neljännessä vaiheessa aineisto tallennettiin ja analysoitiin. Analyysit tehtiin tilastollisin menetelmin, jonka jälkeen tuloksia jouduttiin tulkitsemaan käytännön näkökulmasta. Lopputulokset ovat siten sekä matemaattisen tilastokäsittelyn että inhimillisen kokemusperäisen arvioinnin aikaansaamaa päättelyä. Tutkimuksen läpikäyvänä teemana on eri vaiheissaan ollut pyrkimys tunnistaa pihattojen sellaiset positiiviset rakenteelliset ja toiminnalliset ominaisuudet, jotka tuottavat lehmälle mahdollisimman hyvän terveyden, hyvät tuotanto-olosuhteet, hyvän tuotoksen, hoitajalle hyvän ja mahdollisimman vähäkuormituksisen työympäristön. Tutkimus on kääntäen tarkasteluna tuonut esiin myös ne negatiiviset seikat, jotka toimivat edellä kuvattuja tavoitteita vastaan. Kun nämä faktorit tunnetaan, uusien pihattojen suunnittelussa voidaan keskittyä suosimaan parhaan mahdollisen tuotantoympäristön suunnittelunormeja käytännön rakentamisessa.

\section{Tutkimustilat}

Tutkimustilojen valinta tapahtui siten, että kaikille karjantarkkailussa mukana oleville, keskilehmäluvultaan yli 40 lehmän tiloille $(\mathrm{n}=785)$ lähetettiin kirje, jossa kysyttiin halukkuutta osallistua tutkimukseen. Vapaaehtoisista $(\mathrm{n}=158)$ mukaan valittiin kaikki tilat $(\mathrm{n}=103,65 \%)$ joilla oli tutkimuksen kohteena oleva lämpöeristetty navettatyyppi, ja navetta oli otettu käyttöön vuosien 1990-2002 aikana. Tutkimukseen ei kelpuutettu kombi- tai kylmäpihattoja, vanhoja parsinavettoja tai kestokuivikeratkaisuja. Tietoja karjan hoidosta ja tuotantoympäristöstä kerättiin tiloille lähetetyn kyselykaavakkeen ja 
tilakäynneillä tehdyn havainnoinnin avulla. Karjan tuotos- ja terveystarkkailutiedot saatiin Maatalouden Laskentakeskuksesta. Tutkimusaineisto kerättiin kevään 2005 aikana. Tiloista valtaosalla eli yli 80 \%:1la uusi tuotantotila oli valmistunut 1999 - 2002 välisenä aikana. Kohderyhmä edusti siten kotimaisen pihattosuunnittelun viimeaikaisimpia näkemyksiä ja ratkaisuja. Tutkimuskohdepihattojen keskilehmäluku oli yleisimmin 50 - 59. Hieman yli $80 \%$ lehmistä kuului kokoluokkaan 40 - 69 lehmäpaikkaa. Yli 100 lehmän kohteita oli noin $6 \%$.

\section{Keskeiset tulokset pihaton kannalta}

Parsien tulisi olla keskimäärin nykyistä pehmeämpiä. Parsipeti on suositeltavin parren pintavaihtoehto. Turve tai turpeen ja purun/kutterin seos on suositeltavin kuivikemateriaali. Kuiviketta tulisi useimmilla tiloilla käyttää nykyistä runsaammin. Parsia tulee puhdistaa ja kuivittaa riittävän usein. Parren rakenteet eivät saisi rajoittaa teknisten apuvälineiden tai käsityövälineiden käyttöä, alhaalta avoin parrenerottaja on suositeltavin.

Parsien tulee olla riittävän pitkiä - sijoituspaikasta ja lehmien koosta riippuen $245-300 \mathrm{~cm}$. Suositeltava parren leveys on $130 \pm 10 \mathrm{~cm}$. Parren kaltevuus kannattaa tehdä maltilliseksi, mutta parren pintamateriaali saattaa vaikuttaa sopivaan kaltevuuteen. Parren leveysmitta voidaan suunnitella yksilöllisesti eri eläinryhmille sopivaksi. Leveysmitan ei tarvitse olla sidoksissa rakennuksen kantavien rakenteiden moduuleihin - kuten pilarien -, koska hyvin suunnitellussa pihatossa pilarien ei tarvitse sijaita parsialueilla. Pilarit voidaan tarvittaessa sijoittaa ruokintapöydän reunalinjoihin, joissa ne eivät rajoita parsialueiden mitoittamista.

Parsi tulee säätää lehmille riittävän väljäksi. Niskapuomin oikea paikka on noin $120 \mathrm{~cm}: n$ korkeudessa ja noin $170-180 \mathrm{~cm}$ etäisyydellä parren takaosasta. Lehmän pään edessä ei saa olla minkäänlaisia rakenteita $10-70 \mathrm{~cm}: n$ korkeudella.

Kaksirivinen pihatto on suositeltavin vaihtoehto. Kaksirivisyys takaa ruokintapöydän syöntileveyden riittävyyden ja siten parhaan ruokailurauhan. Lisäksi lehmäliikenne voidaan erotella ruokintakäytävästä erilliseksi parsiliikenteeksi, jolloin ruokintakäytäväliikenne rauhoittuu. Symmetrisessä ratkaisussa $2+2$-rivinen pohja ei vielä tuota liian leveätä rakennusrunkoa, jolloin valon saanti ja ilmanvaihdon painovoimainen toteutus onnistuvat. Lattioiden pintamateriaalien ja valutyön laatuun sekä pintojen viettoon on kiinnitettävä erityistä huomiota. Avokouru suositellaan pinnoitettavaksi kumimatolla.

Ruokintakäytävän suositeltava leveys vaihtelee vähintään 3,40 metristä yli neljään metriin, navetan rivisyydestä riippuen. Parsirivien välisen käytävän leveyden tulee olla 2,40-2,60 m. Poikkikäytävät vaikuttavat lehmäliikenteen sujuvuuteen. Niiden tulee olla tarpeeksi leveitä ja niitä tulee olla riittävästi, noin 15-20 parsipaikan välein. Poikkikäytävien puhdistettavuuteen tulisi kiinnittää huomiota. Lypsylehmien päivittäisessä käytössä olevan pinta-alan vaihtelualue on $8,16-9,4 \mathrm{~m}^{2}$ 2-rivisissä ratkaisuissa ja 7,3-8,7 $\mathrm{m}^{2} 3$ - tai useampirivisissä ratkaisuissa.

Ritiläpalkkien päälle kannattaa asentaa lantaraappa. Avokourujen valun onnistuminen on haasteellista - ongelmat näkyvät muun muassa nesteiden lammikoitumisena. Lantaraappaa tulisi käyttää riittävän usein.

Tunnutettavat hiehot kannattaa siirtää lypsävien ryhmään hyvissä ajoin, olosuhteista riippuen noin 1-2 kk ennen poikimista. Tämä tulisi huomioida lypsävien osaston mitoituksessa. Kiimaiset eläimet kannattaa ottaa eroon muusta joukosta. Navetan suunnittelussa tulisi miettiä myös sitä, missä sairaat eläimet hoidetaan, missä lehmät siemennetään, ja missä lehmien sorkat hoidetaan. Lehmien osasto on hyvä olla jaettavissa useampaan ryhmään - vähintäänkin ummessa olevat on voitava pitää erossa lypsävistä.

Lehmien lypsyliikenne täytyy järjestää mahdollisimman suoriksi reiteiksi lypsyasemalle. Asemalle tulon pitää tapahtua suoraan liikkeen suunnassa: mutkat ja käännökset lehmän reitillä hidastavat lypsyn läpimenoaikaa. Poistumissuuntaan voi olla mutkia. Poistumisreitti ei saa olla liian leveä, koska se mahdollistaa lehmän kääntymisen. Täysimittaisen kokoomatilan tarpeellisuus riippuu lypsettävien ryhmien määrästä ja koosta. Jos pihatossa varaudutaan laajennukseen tulevaisuudessa, kokoomatila on syytä rakentaa laajennusta silmällä pitäen jo ensimmäisessä rakennusvaiheessa. Kokoomatilassa on syytä olla kauko-ohjattava ajolaite (tai koulutettu paimenkoira).

Automaattilypsyyn siirtyneiden tilojen eläinkohtainen karjanhoitotöiden keskimääräinen työnmenekki oli selvästi pienempi kuin muita lypsyjärjestelmiä käyttävien tilojen vastaava työnmenekki. Toimiva, tehokas, järjestelmä edellyttää kuitenkin sitä, että lypsyrobotin rinnalla ei ole toista järjestelmää 
robottiin soveltumattomien lehmien lypsämiseen. Lypsyasematyyppien välinen mahdollinen ero lypsytyöajoissa peittyy tehokkaasti tilakohtaisten tekijöiden, $\mathrm{mm}$. eläinliikennejärjestelyiden, aiheuttamiin vaikutuksiin.

Ruokintapöytätilaa tulee olla riittävästi. Ruokintaesteenä suositeltava vaihtoehto on sellainen, joka on jaettu ruokintapaikkoihin, mutta ei vaikeuta koneellista lannanpoistoa. Vesipisteitä tulee olla riittävästi ja ne tulee sijoittaa niin että ympärillä on riittävästi tilaa ja eikä valuva vesi seiso käytävällä. Väkirehuautomaatteja tulee olla riittävästi, noin yksi 15 lehmää kohden, jos kaikki väkirehu syötetään automaatin kautta.

Vasikan syntymäpaikkana tulisi olla riittävän iso ja hyvin kuivitettu poikimakarsina, jossa on mahdollista olla vierihoidossa päivän pari. Vasikoiden pitopaikka ja olosuhteet tulisi huomioida navettasuunnittelussa nykyistä paremmin. Vanhan navetan käyttö vasikoiden kasvatuspaikkana on usein ongelmallista, sillä niissä on usein puutteellinen ilmanvaihto eikä riittävästi lisälämpöä. Nuorkarjan karsinoissa tulisi suosia vaihtoehtoja, jossa eläimillä on kiinteä makuualue ja karsinassa riittävästi tilaa eläintä kohden. Viimeistään tiineille hiehoille tulisi pihatossa olla makuuparsiosasto.

\section{Lehmän mittaisen makuuparsipihaton uudet mitoitusohjeet}

\begin{tabular}{|c|c|c|}
\hline OSASTOINTI JA RYHMITTELY & minimivaatimus & suomalainen suositus \\
\hline ryhmäkoko & & enintään 70 eläintä \\
\hline ryhmien lukumäärä & 2 & \\
\hline ummessa olevien paikkaluku & lehmäluku x 0,1 & lehmäluku x $0,15 \pm 0,05$ \\
\hline karjaharja & & kyllä \\
\hline
\end{tabular}

Ehdyttäminen ja tunnutus huomioitava, ummessa olevien tila muunneltavissa poikimisten kausivaihtelun mukaisesti.

POIKIMAKARSINAT
yksittäiskarsinan koko
poikimakarsinan koko
poikimakarsinoiden määrä silloin kun
- karja poikii ympäri vuoden
- pääosin $6 \mathrm{kk}: n$ aikana
- pääosin $4 \mathrm{kk}: n$ aikana

minimivaatimus
$10 \mathrm{~m}^{2} /$ lehmä
$8 \mathrm{~m}^{2} /$ lehmä
$0,03 \times$ karjakoko
$0,06 \times$ karjakoko
$0,09 \times$ karjakoko

\begin{tabular}{|c|} 
suomalainen suositus \\
$13 \mathrm{~m}^{2} /$ lehmä \\
$11 \mathrm{~m}^{2} /$ lehmä \\
$0,05 \times$ karjakoko \\
$0,09 \times$ karjakoko \\
$0,13 \times$ karjakoko
\end{tabular}

Yleiset ominaisuudet: vedottomassa paikassa, muunneltava tila josta voidaan erottaa yksittäisiä karsinoita, lehmä helposti kuljetettavissa lypsylle, kuollut/lopetettu eläin helposti poistettavissa, lypsymahdollisuus, kytkentämahdollisuus, karsinassa vesikuppi, karsina runsaasti kuivitettu.

\begin{tabular}{l|c|c|} 
MAKUUPARRET & minimivaatimus & suomalainen suositus \\
lukumäärä & lehmäluku x 1 & lehmäluku x 1,05 \\
parsien leveys keskeltä keskelle & 1,2 & $1,30 \pm 0,10$ \\
parsien pituus, päät vastakkain & & $2,45-2,65$ \\
parsien pituus, seinää vasten & & $2,80-3,10$ \\
parren pinnan kallistus & & $2-3 \%$
\end{tabular}




\begin{tabular}{|c|c|c|}
\hline RUOKINTAPÖYTÄ & minimivaatimus & suomalainen suositus \\
\hline \multicolumn{3}{|l|}{ ruokintapöytätilaa $^{1}$} \\
\hline - lypsylehmät & $\begin{array}{l}1 \text { paikka / } 2 \text { lehmää } \\
\text { tai } 40 \mathrm{~cm} / \text { lehmä }\end{array}$ & $\begin{array}{l}1 \text { paikka / lehmä } \\
\text { tai } 75 \mathrm{~cm} / \text { lehmä }\end{array}$ \\
\hline - hieho $500 \mathrm{~kg}$ & & $65 \mathrm{~cm} /$ eläin \\
\hline - hieho $400 \mathrm{~kg}$ & & $60 \mathrm{~cm} /$ eläin \\
\hline - nuorkarja $300 \mathrm{~kg}$ & & $55 \mathrm{~cm} /$ eläin \\
\hline - nuorkarja $200 \mathrm{~kg}$ & & $50 \mathrm{~cm} /$ eläin \\
\hline - nuorkarja $150 \mathrm{~kg}$ & & $40 \mathrm{~cm} /$ eläin \\
\hline - nuorkarja $100 \mathrm{~kg}$ & & $35 \mathrm{~cm} /$ eläin \\
\hline - nuorkarja 60 kg & & $30 \mathrm{~cm} /$ eläin \\
\hline $\begin{array}{l}\text { ruokintapöydän pinnan korkeus } \\
\text { suhteessa lehmän seisontatasoon }\end{array}$ & & $10-20 \mathrm{~cm}$ \\
\hline \multicolumn{3}{|l|}{ syöttöparret } \\
\hline $\begin{array}{l}\text { - korkeus lantakäytävätasosta } \\
\text { - pituus } \\
\text { - kallistus }\end{array}$ & & $\begin{array}{c}0 \text { tai } 10 \mathrm{~cm} \text {, jos korotettu } \\
1,60 \mathrm{~m} \\
2-3 \%\end{array}$ \\
\hline sorkkapallin korkeus (ei välttämätön) & & $5-10 \mathrm{~cm}$ \\
\hline sorkkapallin syvyys (ei välttämätön) & & $20-30 \mathrm{~cm}$ \\
\hline
\end{tabular}

${ }^{1}$ Kaikkien lehmien tulee pääsääntöisesti mahtua syömään yhtä aikaa.

\begin{tabular}{l|c|c|} 
JUOMAVESI & minimivaatimus & suomalainen suositus \\
- lämpötila & & $15-20{ }^{0} \mathrm{C}$ \\
- virtaus & $101 / \mathrm{min}$ & $10-201 / \mathrm{min}$ \\
- kuppien $\varnothing>30 \mathrm{~cm}$ lukumäärä & $1 \mathrm{kpl} / 6$ lehmää & $1 \mathrm{kpl} / 4$ lehmää \\
- yläreunan korkeus lattiatasosta & $70 \mathrm{~cm}$ & $70-90 \mathrm{~cm}$ \\
- vesialtaan tilavuus & & $200 \pm 501$ \\
- vesialtaiden määrä & $>10 \mathrm{~cm} /$ lehmä & $<20$ lehmää / allas
\end{tabular}

Vesipisteet sijoitetaan tasaisesti, juomakuppien ja/tai välinen etäisyys $>2 \mathrm{~m}$, altaan likaantuminen estetään korokkeella tai kaiteella.

\begin{tabular}{|c|c|c|}
\hline VÄKIREHUAUTOMAATTI & minimivaatimus & suomalainen suositus \\
\hline väkirehuautomaattien lukumäärä ${ }^{1}$ & 1 / 25 lehmää & 1 / 15 lehmää \\
\hline
\end{tabular}

${ }^{1}$ jos kaikki väkirehu syötetään automaatin kautta 


\begin{tabular}{l|c|c|} 
LANTAKÄYTÄVÄT & minimivaatimus & suomalainen suositus \\
ruokintakäytävän leveys & \\
- 2-rivinen ratkaisu & $3,40-3,60 \mathrm{~m}$ \\
- 3-rivinen ratkaisu & $3,60-3,80 \mathrm{~m}$ \\
- 4-rivinen ratkaisu & 4 tai enemmän \\
parsirivien välinen lantakäytävä & $2,40-2,60$ \\
poikkikäytävien leveys & \\
- yleensä & $1,8 \mathrm{~m}$ \\
- jos vesiallas tai karjaharja & $3,3-3,6 \mathrm{~m}$ \\
- jos vesiallas ja karjaharja & $4-5 \mathrm{~m}$ \\
poikkikäytävien lukumäärä & & $1 / 15-1 / 20$ partta
\end{tabular}

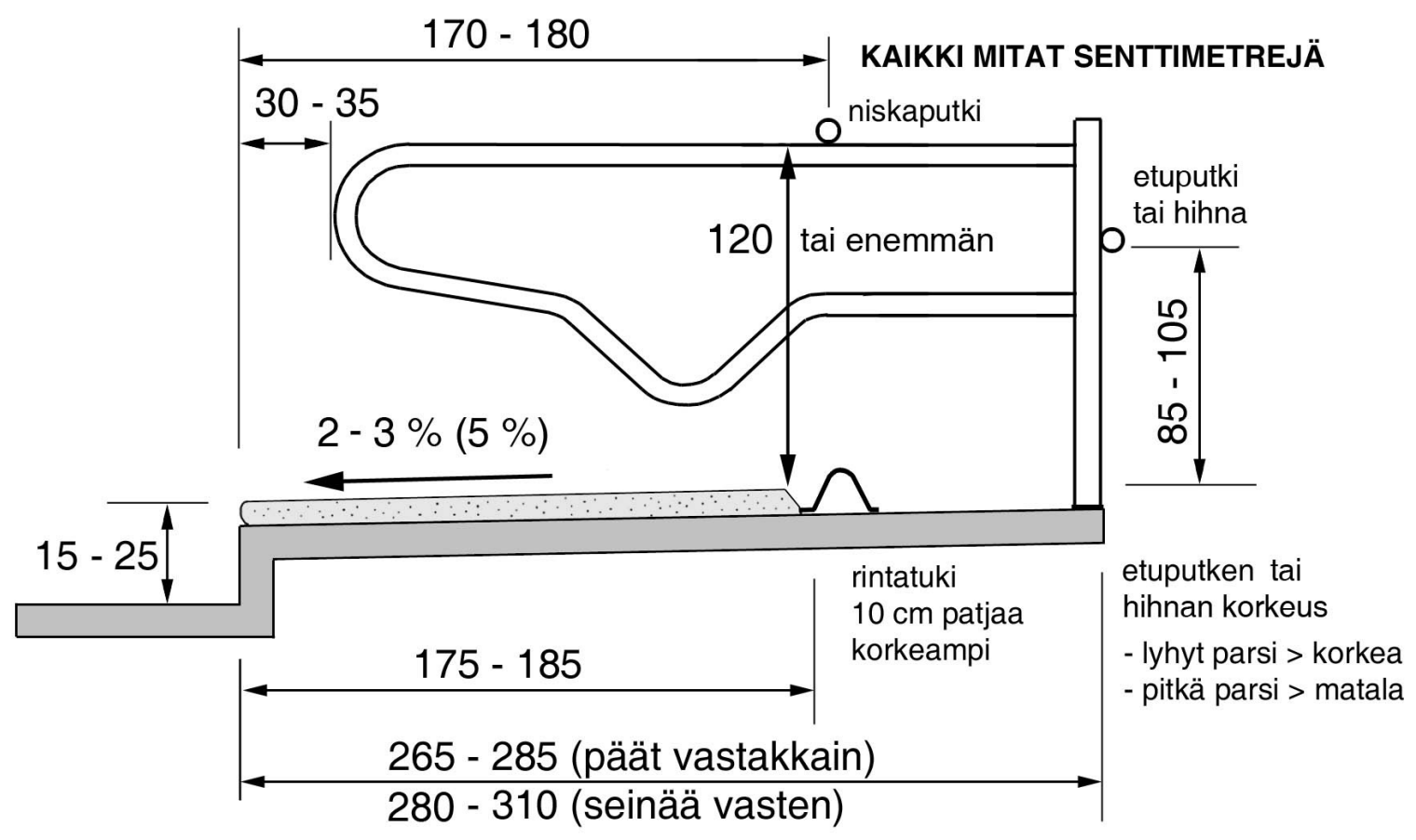

Kuva 2. Pihaton parren poikkileikkauskuva suositeltuine mittoineen.

\section{Loppupäätelmät}

Suomessa oli vuoden 2006 lopussa noin 15350 maitotilaa. Maito tuotetaan edelleen pääasiassa perinteisissä parsinavetoissa, joiden keskikoko on noin 15 lehmää. Makuuparsipihattoja on vasta noin 20 \%:lla kaikista maidontuotantotiloista. Tätä loppuraporttia kirjoitettaessa maitotilojen lukumäärä vähenee noin kolmella tilalla päivässä. Maidontuotannon lopettavat tilat ovat suurimmaksi osaksi karjamäärältään pieniä, ja uudet rakennettavat yksiköt ovat useimmiten noin 60 lypsylehmän suuruisia. Vuonna 2015 Suomessa ennustetaan olevan noin 7500 ja vuonna 2020 noin 5500 maidontuotantotilaa. Rakennekehitys johtaa lähes vääjäämättömästi siihen, että maidontuotantoa pitkään jatkavat tilat tarvitsevat joko voimakkaasti laajennetut tuotantorakennukset tai kokonaan uudet rakennukset. Uuden tuotantokapasiteetin rakentaminen on kansantaloudellisesti merkittävä ponnistus. Tällä hetkellä pihatoissa on noin $30 \%$ lehmistä. Jos lehmämäärä pysyy nykyisessä 300 000:ssa, uusia lehmäpaikkoja tarvitaan 210000 kpl. Jos lehmäpaikan kustannus pysyy 6 000-10 $000 €$ :n haarukassa, se merkitsee $12-21 \mathrm{mrd} €: n$ investointeja uuteen rakennuskantaan.

Tämä tutkimus on osoittanut, että lehmän tuotantokyvyn ja samalla hyvinvoinnin samanaikainen toteuttaminen edellyttävät riittävää väljyyttä lehmän arkipäivän toimintaympäristössä ja tehokkaita 
tekniikkaratkaisuja hoitajan työmäärän ja jaksamisen optimoimiseksi. Tämä yhdistelmä on kyllin perusteltu syy suunnitella uudet maidontuotantorakennukset oikein, jotta panostuksilla ei aiheutettaisi hukkainvestointeja niin kansantalouden kuin yksittäisen tilatason ratkaisuissa. Tämän tutkimuksen yksi kantavista ajatuksista onkin ollut selvittää tähänastisten pihattoratkaisujen hyvät ominaisuudet, joita kannattaa suosia uusissa suunnitelmissa. Näin lehmän tuotos ja hyvinvointi sekä hoitajan työ saadaan parhaaseen tuotannolliseen iskuun.

\section{Kirjallisuuslähteet}

Anon. 2002. Interdisciplinary report "Housing design for cattle - Danish recommendations. Third edition 2001". $1-122$.

Dansk Landbrugsrådgiving Landscentret. 2005. Indretning af stalde till kvæg - Danske anbefalinger. Tæ rfaglig rapport. 4. udgave. $68 \mathrm{~s}$.

Hultgren, J. 2002. Foot/leg and udder health in relation to housing changes in Swedish dairy herds. Prev. Vet Med $53: 167-189$.

Hultgren, J. ja C. Bergsten 2001. Effects of a rubber-slatted flooring system on cleanliness and foot health in tied dairy cows. Prev. Vet Med 52:75-89.

Huzzey, J.M., DeVries, T.J., Valois, P. ja von Keyserlingk, M.A.. Stocking density and feed barrier design affect the feeding and social behavior of dairy cattle. J.Dairy Sci. 89 (1):126-133, 2006.

Kaihilahti, J., S. Raussi, H. Khalili ja J. Sariola. 2006. Cow behaviour and disturbances at automatic concentrate feeder. Proceedings of XVI CIGR World Congress/AgEng Bonn 2006/64 ${ }^{\text {th }}$ VDI-MEG International Conference Agricultural Engineering: 543-544.

Karttunen, J. 2004a. Maidontuottajien teknologiavalinnat suurissa tuotantoyksiköissä - Karkearehun käsittelyketjut ja karjanhoitotöiden työnmenekki. Työtehoseuran julkaisuja $394.73 \mathrm{~s}$.

Karttunen, J. 2004b. Karkea- ja seosrehun jako naudoille. Teoksessa: Puumala, L., M. Yliaho, H. Teräväinen. (toim.). Nauta- ja sikatilan ruokintastrategia. ProAgria Maaseutukeskusten Liitto. Tieto Tuottamaan 106: 52-58.

Karttunen, J. ja V-M. Tuure. 2006. Maidontuotanto suurissa pihatoissa - Karjanhoitotöiden organisointi. Työtehoseuran maataloustiedote (586) $1.8 \mathrm{~s}$.

Karttunen, J. ja M. Peltonen. 2004. Lypsyn ja puhtaanapitotöiden työnmenekki pihatossa. Teoksessa: UusiKämppä, J. \& Rissanen, P. (toim.). Suuret pihatot - eläinten hyvinvointi, lypsyn työnmenekki, työolot ja ympäristönhoito. Maa- ja elintarviketalouden tutkimuskeskus. Ympäristö. Maa- ja elintarviketalous 47. s. 58-70.

Krötzl, H. 1995. Parresta pihattoon, naudan lajinmukainen käyttäytyminen rakentamisen perustana.

Ontario Ministry of Agriculture and Food. 2003. Freestall Housing Manual. Monistesarjoja suunnittelukansiossa.

The Danish Agricultural Advisory Center. 2002. Housing Design for Cattle. Interdisciplinary report. Third edition 2001. $120 \mathrm{~s}$.

Tuotantoeläinten hyvinvointistrategia 2006. Maa- ja metsätalousministeriö

Uusi-Kämppä, J., Rissanen, P. 2004. Suuret pihatot - eläinten hyvinvointi, lypsyn työnmenekki, työolot ja ympäristönhoito. Maa- ja elintarviketalous 47: $184 \mathrm{~s}$. 